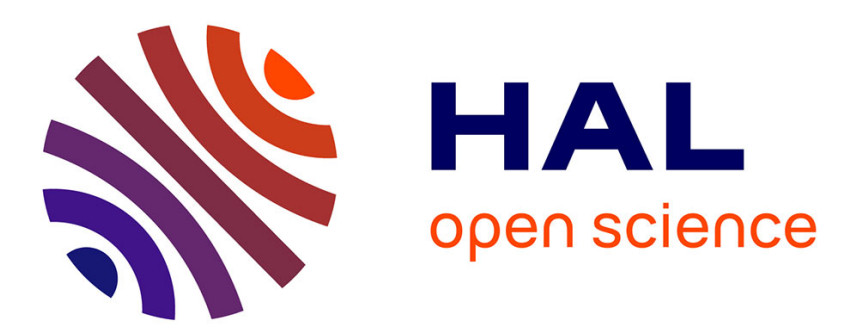

\title{
Cyclic oxidation of high-silicon spheroidal graphite iron
} André Ebel, Olivier Marsan, Jacques Lacaze, Benoit Malard

\section{To cite this version:}

André Ebel, Olivier Marsan, Jacques Lacaze, Benoit Malard. Cyclic oxidation of high-silicon spheroidal graphite iron. Corrosion Science, 2021, 192, pp.109854. 10.1016/j.corsci.2021.109854 . hal-03362964

\section{HAL Id: hal-03362964 https://hal.science/hal-03362964}

Submitted on 2 Oct 2021

HAL is a multi-disciplinary open access archive for the deposit and dissemination of scientific research documents, whether they are published or not. The documents may come from teaching and research institutions in France or abroad, or from public or private research centers.
L'archive ouverte pluridisciplinaire HAL, est destinée au dépôt et à la diffusion de documents scientifiques de niveau recherche, publiés ou non, émanant des établissements d'enseignement et de recherche français ou étrangers, des laboratoires publics ou privés. 
Cyclic oxidation of high-silicon spheroidal graphite iron

André EBEL ${ }^{1}$, Olivier MARSAN, Jacques LACAZE, Benoit MALARD

Centre inter-universitaire de recherche et d'ingénierie des matériaux (CIRIMAT), UMR 5085 - CNRS/INPT/UPS, 4 allée Emile Monso, BP44362, 31030 Toulouse Cedex 4, France

Corresponding author: Jacques LACAZE, jacques.lacaze@ensiacet.fr

\begin{abstract}
In service, automotive exhaust manifolds are submitted to rapid thermal cycling up to 700$750^{\circ} \mathrm{C}$. To simulate an increase in exhaust gas temperature, a high-silicon cast iron was tested for rapid thermal cycling up to $800^{\circ} \mathrm{C}$. In addition to the well-known duplex oxide scale, rapid cyclic oxidation promotes the formation of a columnar zone at the substrate/oxide interface that has never been reported. It is evidenced that this columnar zone proceeds from a repetitive process. Based on detailed metallographic analysis using optical observations, in-situ XRD, micro-analyses and Raman spectroscopy, a mechanism explaining the formation of this columnar zone is proposed.
\end{abstract}

\title{
Keywords:
}

A: iron; B: thermal cycling; B: Raman spectroscopy; B: X-ray diffraction; C: oxidation

1. Present address: Laboratoire des composites thermostructuraux (LCTS)

UMR 5801 - Safran/CEA/CNRS/Univ.Bordeaux

3 Allée de la Boétie, 33600 Pessac, France 


\section{Introduction}

Due to a combination of good casting ability, mechanical properties, corrosion resistance and low cost, spheroidal graphite cast irons (SGI) are commonly used for complex parts requiring high material performances [1]. Within this family of materials, high-silicon SGI with 3.5-4.5 wt.\% silicon (Hi-Si SGI) have been developed for service at intermediate to high temperature [2]. The primary effect of silicon addition is to significantly increase the eutectoid temperature and thus to extend the temperature range without phase change of the cast iron matrix [3]. However, the maximum service temperature may be limited by additional phenomena such as surface oxidation, subsurface decarburization and graphite coarsening that can take place below the eutectoid transformation temperature.

In Fe-Si alloys and Hi-Si SGI, isothermal oxidation proceeds with the formation of a thin, protective layer of silicon-rich oxide, followed by rapidly growing iron oxide nodules. Over time, these nodules expand laterally and eventually cover the entire sample surface [4]. The resulting scale consists of an outward growing layer composed of magnetite $\left(\mathrm{Fe}_{3} \mathrm{O}_{4}\right)$ and hematite $\left(\mathrm{Fe}_{2} \mathrm{O}_{3}\right)$ and an inward growing layer of magnetite, wüstite $(\mathrm{FeO})$ and fayalite $\left(\mathrm{Fe}_{2} \mathrm{SiO}_{4}\right)$, as well as a Si-rich oxide at the metal-oxide interface $[5,6]$. The iron oxide nodules are clearly associated with graphite or carbide particles in the case of SGI [4] while their formation on Fe-Si alloys is still unclear [7]. High Si contents favour silica $\left(\mathrm{SiO}_{2}\right)$ formation at the metal-oxide interface that acts as diffusion barrier [8] and reduces oxidation kinetics even if it is discontinuous [9]. Further, silica formation is favoured when temperature increases from $700^{\circ} \mathrm{C}$ to $800^{\circ} \mathrm{C}$ and this leads to a decrease in oxidation kinetics of Fe-Si alloys [7]. Accordingly, increasing the oxidation temperature of Hi-Si SGI up to $800^{\circ} \mathrm{C}$ in air does not have a strong effect on the amount of oxide formed. However, this has a marked effect on the scale morphology which changes from an even layer to a highly uneven one $[10,11]$. The oxide scale evenness and its formation rate are also affected by water vapour [10] and previous work [12] related the effect of water vapour to the

promotion of internal oxidation of silicon within the metallic matrix instead of the formation of dense silica at the metal-oxide interface. 
In the case of SGI, decarburization refers to the dissolution of graphite particles in the matrix and this occurs when carbon is oxidized into gaseous carbon oxide at the specimen surface. While it remains unclear if carbon oxidation takes place at the metal-oxide interface, in the oxide scale or at the oxide-gas interface, elemental carbon or the gaseous carbon oxide resulting from carbon oxidation has to diffuse through the oxide scale for decarburization to keep proceeding. This phenomenon has been observed above $700^{\circ} \mathrm{C}$ for low-Si cast-iron [13] and above $800^{\circ} \mathrm{C}$ for Hi-Si SGI [14], and its rate increases with temperature. The interaction between oxidation and decarburisation are two-fold: on the one hand, decarburisation affects the oxide morphology and the oxidation rate, as reported by Lekakh et al. [10,11]; on the other hand, the formation of oxides could limit the decarburisation rate assuming that Si-rich oxides also act as an effective diffusion barrier for carbon. Accordingly, water vapour was found to fasten decarburization on Hi-Si SGI at $800^{\circ} \mathrm{C}$ as it promotes internal oxidation of silicon rather than formation of a protective dense silica scale [12].

Thermal cycling below the eutectoid temperature has no effect on oxide scale adhesion and graphite structure beside decarburization for long exposure time at peak temperature (1 hour) [15]. However, recent results with a short exposure time at a peak temperature of $800^{\circ} \mathrm{C}$ (60 seconds) have shown that thermal cycling can trigger coarsening and degeneration of the graphite particle shape [16]. Very little work has been devoted to oxidation under thermal cycling with such short exposure time at peak temperature while this should be more representative of the use of Hi-Si cast iron for high temperature applications like passenger car exhaust systems. The present work thus focused on the effect of thermal cycling with short exposure time and large number of cycles on oxidation of Hi-Si SGI with a peak temperature at $800^{\circ}$ C. Samples after 1000, 2000 and 3000 cycles were characterized using various techniques, and compared to a reference sample that was oxidized under isothermal conditions at $800^{\circ} \mathrm{C}$. In the discussion of the results, a schematic is proposed for explaining the observation of a repetitive columnar zone at the interface between the matrix and the inner oxide scale that appears to be instrumental in the complex mechanism of cast iron oxidation. 


\section{Materials \& Methods}

\section{Material preparation}

The material was a Hi-Si near-eutectic SGI with 4.45 wt.\% Si that was labelled alloy \#4 in the previous work where all casting details are given [17]. Ten plate-like samples, $20 \mathrm{~mm}$ in height, $10 \mathrm{~mm}$ in width and $2 \mathrm{~mm}$ in thickness were cut out from the casting for thermal cycling tests and a $1 \mathrm{~mm}$ diameter hole was drilled for hanging. Two more samples were prepared, a thick one ( $6 \mathrm{~mm}$ in thickness) and a thin one ( $2 \mathrm{~mm}$ in thickness) for isothermal oxidation and for high-temperature X-ray diffraction (HT-XRD). Before testing, the samples were polished with SiC papers (1200 grit), then cleaned with acetone and finally dried. Actual dimensions of each specimen were measured using a Vernier calliper $( \pm 10 \mu \mathrm{m}$ accuracy), and those specimens for oxidation experiments were also weighted using a Sartorius Genius ME215-P precision balance with a weighing capacity of $210 \mathrm{~g}$ (readability of $50 \mu \mathrm{g}$ and reproducibility of $20 \mu \mathrm{g}$ according to the documentation).

\section{$\underline{\text { Oxidation tests }}$}

The isothermal heat treatment was carried out in a resistance furnace set at $800^{\circ} \mathrm{C} \pm 2{ }^{\circ} \mathrm{C}$. The sample referred to as "isothermal" in the following was held for 50 hours in the furnace, after which it was removed and cooled in the open air.

Thermal cycling was performed using an in-house facility that has been previously described [18]. The 10 plate-like samples are suspended to a holder with thin platinum wires, with one of the samples fitted with a thermocouple to continuously record temperature changes over time. The sample holder is attached to a mechanical cylinder that moves it up and down. At the lower position of the cylinder, the specimens are air cooled by a fan. At the upper position, the specimens are heated in a resistance furnace. The whole system is open to the air.

An automatic cycling procedure was defined, consisting of: 1) Moving the specimen holder to the upper position; 2) Maintaining the holder in the upper position until the specimens 
spent 60 seconds in the temperature range of $800 \pm 10^{\circ} \mathrm{C}$; 3) Moving the holder to the lower position; 4) Holding the specimens in front of the fan until the specimen temperature is lowered to $70-90^{\circ} \mathrm{C}$. The parameters of this thermal cycling procedure are the holding time in the upper position in the furnace, $t_{h o t}$, and the holding time in the lower position in front of the cooling fan, $t_{\text {cold }}$. This process was repeated up to 3000 times, though interrupted every 200 cycles for measuring the mass of the specimens. For this purpose, all the specimens were removed from the holder and were weighted using the same Sartorius precision balance. The mass change of each specimen, $\Delta m$, was normalized with its external original surface, $S$, to obtain specific mass variations $(\Delta m / S)$.

After completion of 1000 cycles, 3 specimens were removed from the system and stored for analysis. This was repeated at 2000 cycles and after 3000 cycles the last three samples were withdrawn. Thus, at the end of 3000 cycles, three specimens had undergone 1000 cycles, three more 2000 cycles and three others had completed 3000 thermal cycles.

For constant thermal cycling parameters $t_{\text {hot }}$ and $t_{\text {cold }}$, preliminary tests demonstrated that the maximum temperature of the specimens increased and the minimum temperature decreased after removing three samples from the holder. Therefore, the parameters $t_{\text {hot }}$ and $t_{\text {cold }}$ were reduced after 1000 cycles and again after 2000 cycles, so that the control temperature does not exceed $810^{\circ} \mathrm{C}$ upon heating and does not fall below $70^{\circ} \mathrm{C}$ upon cooling. The appropriateness of the new parameters was checked with the first cycles following the changes. Typical temperature-time curves during the first, second and third periods of 1000 cycles are illustrated in Fig. 1 -a. The time spent in the $800^{\circ} \mathrm{C}+/-10^{\circ} \mathrm{C}$ range after completion of 3000 cycles actually reaches 56 hours, which is comparable to the duration of isothermal heat treatment (50 hours). However, while these two heattreatments result in roughly the same duration at peak temperature, thermal cycling with such short exposure time at peak temperature adds non-negligible oxidation time at intermediate temperature during heating and cooling steps with the total duration of the exposure at temperature in between $690^{\circ} \mathrm{C}$ and $790^{\circ} \mathrm{C}$ reaching 80 hours after 3000 cycles. This is seen with the histogram of cumulated durations spent in the range $690-810^{\circ} \mathrm{C}$ after 3000 cycles that is presented in Fig. 1-b. 

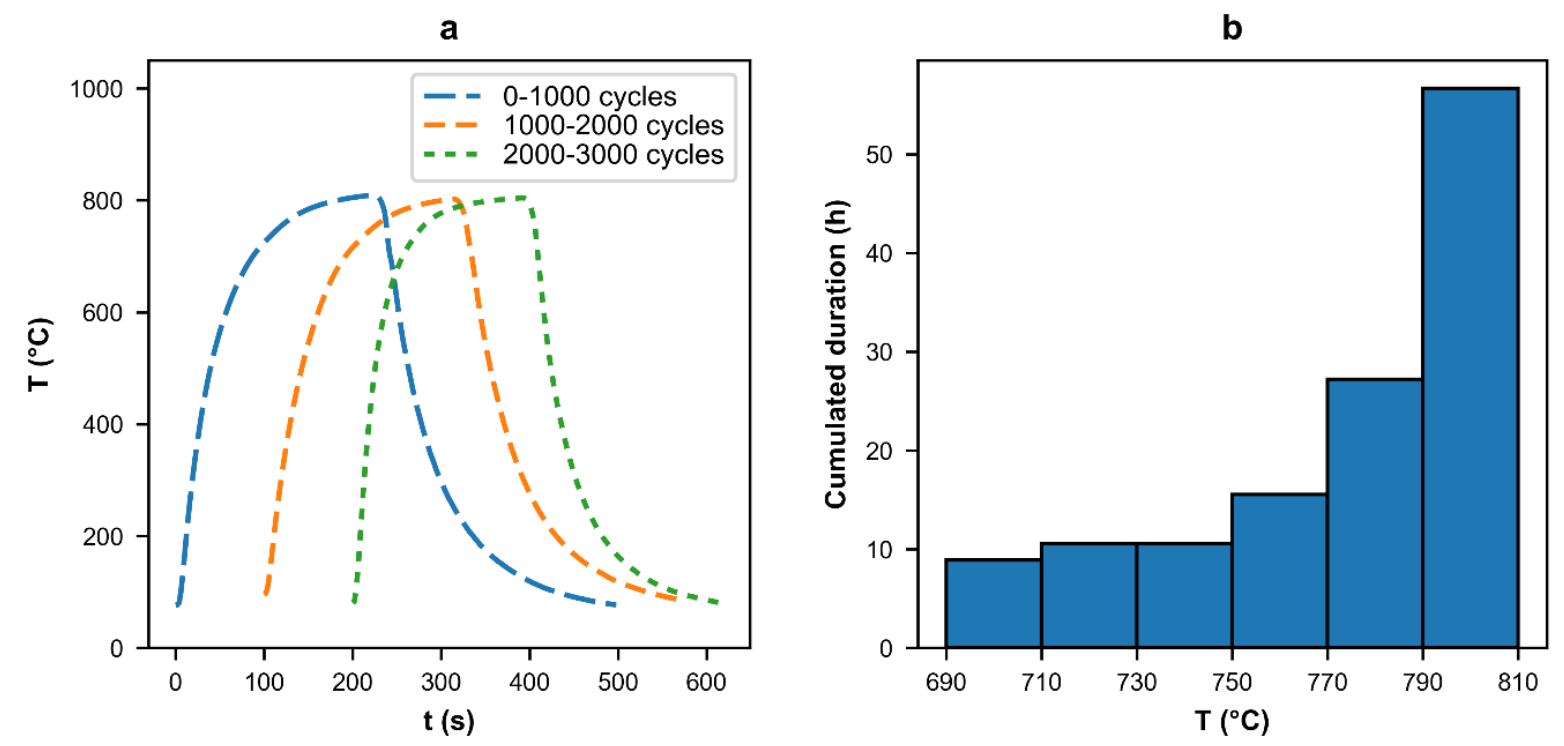

Fig. 1. a: Examples of thermal cycle measured between 0 and 1000 cycles, 1000 and 2000 cycles and between 2000 and 3000 cycles. b: Histogram of the cumulated time spent in the range $690-810^{\circ} \mathrm{C}$ after 3000 cycles considering the evolution of the thermal cycles.

\section{Characterization Methods}

Four specimens, i.e. the isothermally heat-treated specimen and one specimen for each cycling period (1000, 2000 and 3000 cycles), were prepared for metallographic observations. A Secotom 50 Struers micro-chainsaw was used to make a vertical cut along each sample. One half was kept for surface observation and the other one was hot mounted and polished using SiC paper and diamond cloths. Polished cross-sections were cleaned in an ultrasonic bath in ethanol before observation. Surface and cross section observations were performed with an optical Zeiss AX10 microscope. Additional observations were performed using a FEI Quanta 450 scanning electron microscope (SEM) equipped with a Bruker Quantax electron dispersive spectrometer (EDS). Imaging was performed with accelerating voltage between 5 and $12 \mathrm{kV}$. EDS composition measurements were then made quantitative using the PhiRhoZ method after calibration. 
Raman spectroscopy was used to perform point analyses and mappings on cross sections. The setup used is a confocal RAMAN Labram HR 800 Horiba Yvon Jobin microscope coupled to a $532 \mathrm{~nm}$ solid laser with a power of $12 \mathrm{~mW}$. Attenuation filters for lowering the laser power by a factor of ten were used to avoid any degradation of the samples. In this facility, the sample is positioned under an Olympus BX 41 microscope with an objective x 100 which gives a lateral resolution of $0.72 \mu \mathrm{m}$ and an axial resolution of $2.61 \mu \mathrm{m}$. A silicon standard enabled the equipment to be frequency calibrated using the first order line of silicon at $520.7 \mathrm{~cm}^{-1}$ with an accuracy of $\pm 1 \mathrm{~cm}^{-1}$. The spectrum of each point was acquired with a spectral resolution of $1 \mathrm{~cm}^{-1}$ and collected with a quantum well detector cooled to $60^{\circ} \mathrm{C}(\mathrm{CCD}$ Synapse).

The maps were recorded using an XYZ motorized table having a position accuracy of $0.1 \mu \mathrm{m}$ in each direction. Mapping was done with a step of $1 \mu \mathrm{m}$ in both $\mathrm{X}$ and $\mathrm{Y}$ directions, and the spot size of the laser was estimated to about $1 \mu \mathrm{m}$. To adjust the focus of the laser, the system is equipped with an autofocus whose amplitude range is optimized according to the roughness of the studied area. The spectrum for each point of the maps was obtained by accumulating three successive spectra during 30 second each. Data processing was afterwards performed using the Labspec 6 software.

\section{$\underline{\text { In-situ high temperature XRD experiments }}$}

In addition to the isothermal oxidation and thermal cycling experiments, in-situ X-ray diffraction measurements were carried out at high temperature to investigate the early steps of oxidation and possible phase transformations.

Two experiments were carried out: experiment $\mathrm{n}^{\circ} 1$ with measurements at temperatures between 100 and $750^{\circ} \mathrm{C}$, and experiment $\mathrm{n}^{\circ} 2$ with four successive thermal cycles between $100^{\circ} \mathrm{C}$ and $800^{\circ} \mathrm{C}$. For each experiment, XRD acquisition was carried out during the hold steps at constant temperature as depicted on Fig. 2. Heating and cooling rates were $1{ }^{\circ} \mathrm{C} / \mathrm{s}$, and the holding time at each temperature was limited to the acquisition time. Both 
experiments were performed in argon at atmospheric pressure, i.e., corresponding to an oxygen partial pressure $\mathrm{P}\left(\mathrm{O}_{2}\right)$ of about $10^{-5}$ atm.

HT-XRD measurements were performed using a high-temperature X-ray diffraction setup consisting in a Bruker D8 Discover diffractometer equipped with a $\mathrm{Cu} K_{\alpha}(1.5418 \mathrm{~A}) \mathrm{X}$-ray tube operated at $40 \mathrm{kV}$ and $40 \mathrm{~mA}$, a nickel filter, a solid-state 1-D Lynx-eye detector and a high temperature furnace. These measurements enabled identification of the phases at the specimen surface as well as their lattice parameters, crystallite size and micro-strain evolution during high temperature oxidation.

Before running the experiments on Hi-Si SGI, the pseudo-Voigt peak broadening related to the instrument configuration was evaluated using a $L a B_{6}$ standard powder sample from the National Institute of Standards and Technology (NIST). This method enabled the determination of the Caglioti parameters $(\mathrm{U}, \mathrm{V}, \mathrm{W}$ for Gaussian components and $\mathrm{X}, \mathrm{Y}$ for the Lorentz components) in order to perform the deconvolution of the signal due to the instrumental configuration and to obtain the quantification of the physical parameters such as average crystallite size and micro-strain.

After this calibration, measurements were performed on Hi-Si SGI specimens with a $\theta-\theta$ mounting, from $2 \theta=40^{\circ}$ to $102^{\circ}$, with a step of $0.02^{\circ}$ for an acquisition time of 1 seconds per point. The total acquisition time was 2400 seconds (40 minutes). With these parameters, the X-ray penetration depth in ferrite is evaluated to increase from $1 \mu \mathrm{m}$ at $40^{\circ}$ to $4.5 \mu \mathrm{m}$ at $102^{\circ}$ during the scan.

Phase identification, phase lattice parameter, crystallite size (Lorentz contribution) and micro-strain (Gaussian contribution) determinations were performed on each diffraction pattern using the Topas software [19] following the Rietveld Method [20]. For convenience, background was subtracted from the diffraction patterns before plotting. 

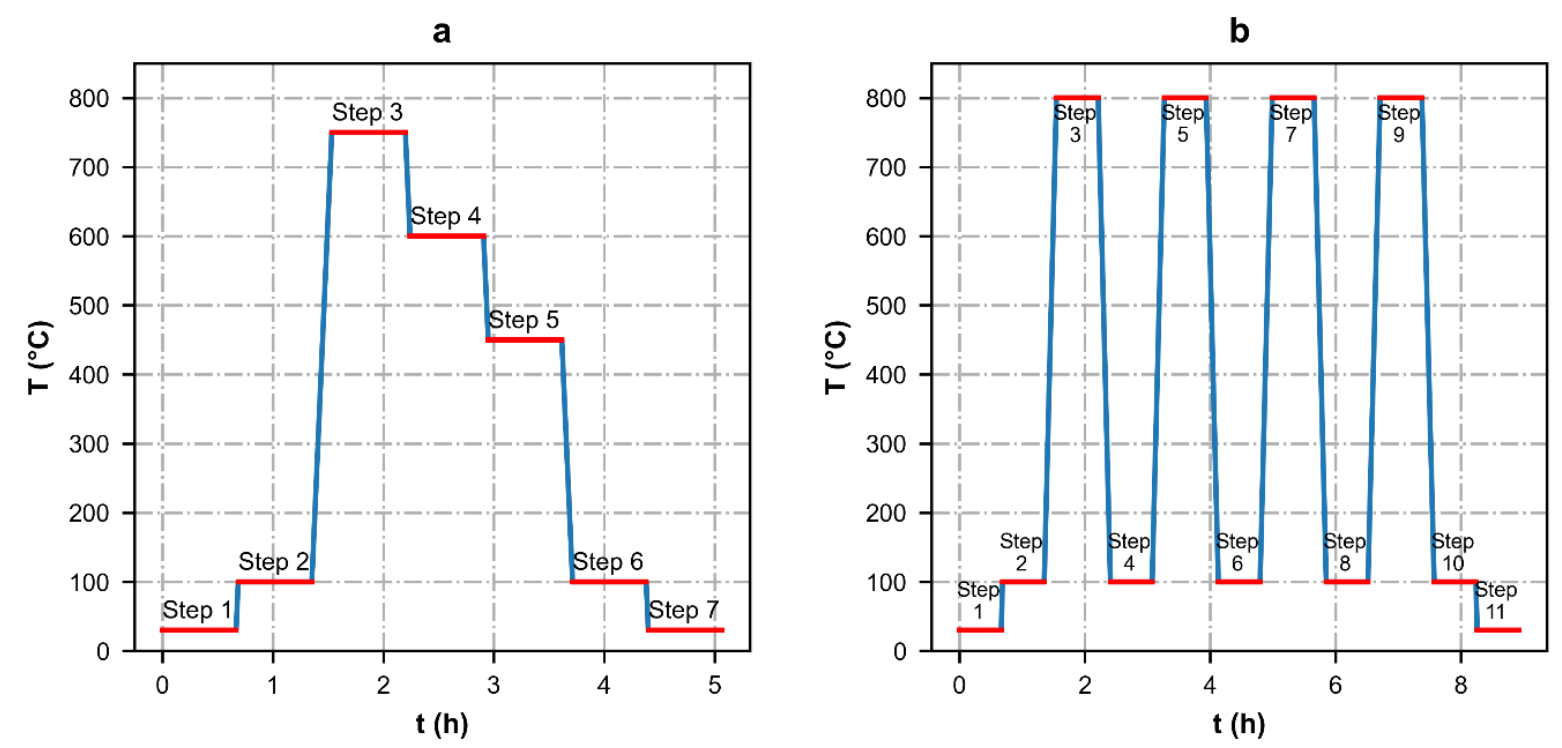

Fig. 2: Temperature profiles of the in-situ HT-XRD experiment $n^{\circ} 1$ (a) and experiment $n^{\circ} 2$ (b) carried out in this work on Hi-Si SGI. Red lines indicate the XRD acquisition steps.

\section{Results}

The in-situ HT-XRD experiments are presented first because these results are key to understanding many other observations. This is followed by metallographic analysis of the oxide scales and then oxidation and decarburization kinetics are presented.

\section{$\underline{\text { In situ high temperature X-ray diffraction }}$}

The diffraction patterns obtained during in-situ HT-XRD experiment $n^{\circ} 1$ up to $750^{\circ} \mathrm{C}$ (see thermal cycle on Fig. 2-a) presented only ferrite peaks. On the contrary, the diffraction patterns recorded during in-situ HT-XRD experiment $\mathrm{n}^{\circ} 2$ (see the thermal cycles in Fig. 2-b) that are displayed on Fig. 3-a clearly show that austenite peaks were detected along with ferrite peaks when the specimen was heated up to $800^{\circ} \mathrm{C}$. These austenite peaks disappear and only ferrite is detected after cooling again the specimen down to $100^{\circ} \mathrm{C}$. As expected, some oxidation took place and hematite was also clearly detected on all diffraction patterns 
after the second heating to $800^{\circ} \mathrm{C}$ (step 5 and later steps). The formation of austenite was unexpected as the three-phase ferrite-austenite-graphite field for the nominal composition of the studied alloy is located at temperature higher than $860^{\circ} \mathrm{C}[16]$. This important observation will be discussed later.
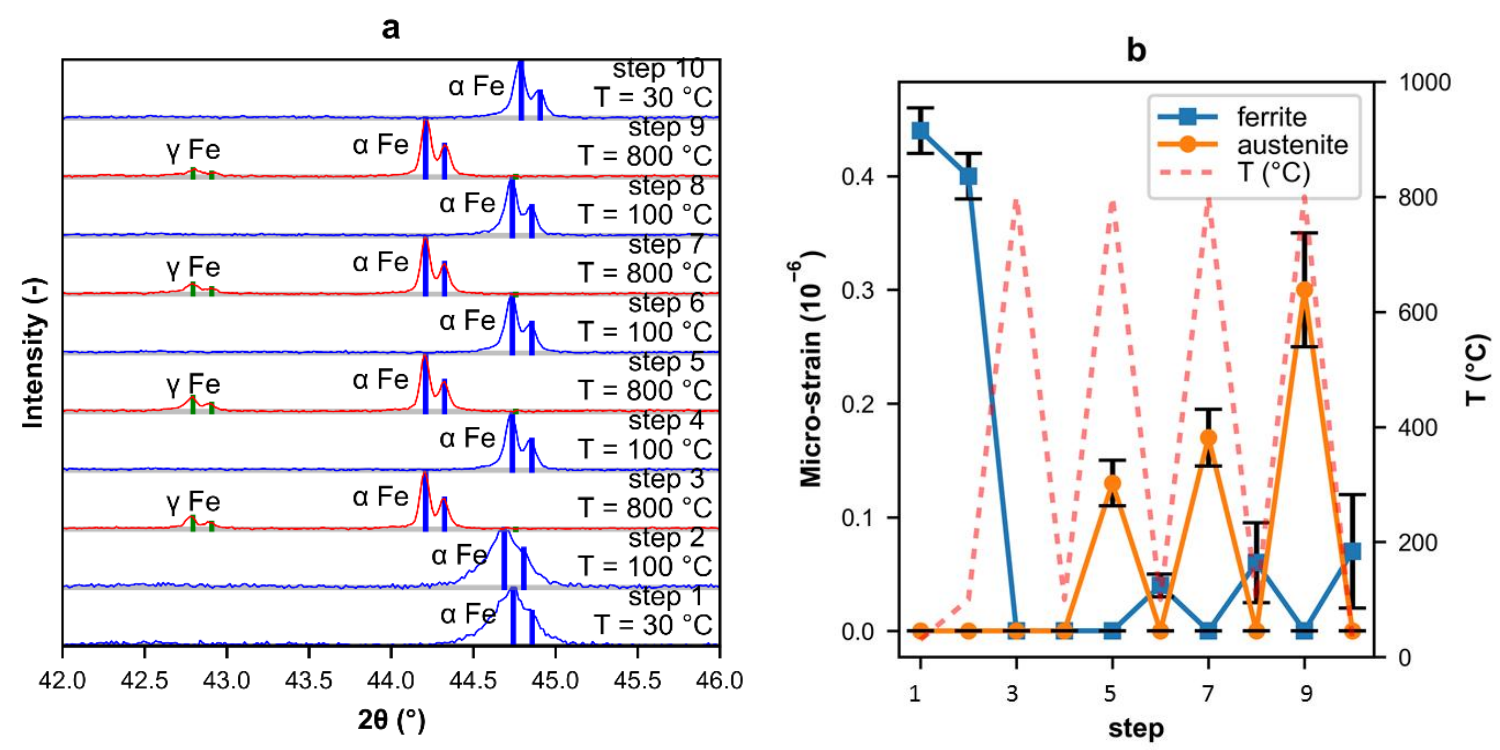

Fig. 3. Part of the in-situ X-ray diffraction patterns of experiment $n^{\circ} 2$ showing the most significant ferrite and austenite peaks (a) and the micro-strains identified with the Rietveld method in these phases during thermal cycling (b).

During both experiments $\mathrm{n}^{\circ} 1$ and $\mathrm{n}^{\circ} 2$, the first heating up to $750^{\circ} \mathrm{C}$ or $800^{\circ} \mathrm{C}$ led to a drop in micro-strain in ferrite which is manifested by a decrease of the width of the ferrite peak observed between steps 2 and 3 on fig. 3-a. It is correlated to a drop in micro-strain (Fig. 3b ) and to a large increase of its average crystallite size as calculated by the Rietveld method (not shown here). The measurement of micro-strain also reveals that the formation of austenite at $800^{\circ} \mathrm{C}$ is not accompanied by micro-strain during the first heating to $800^{\circ} \mathrm{C}$ (step 3). However, micro-strain in austenite is identified during the second thermal cycle (step 5) and the micro-strain level then increases with further thermal cycling. After the second cooling down to $100^{\circ} \mathrm{C}$ (step 6), some micro-strain is also identified in the ferrite phase that may be inherited from austenite. In the same way as for austenite, the level of 
micro-strain detected in ferrite increases with the number of cycles (steps 8 and 10). Based on these measurements, it can be assumed that the austenite formed during isothermal oxidation is micro-strain free and that the micro-strain identified in austenite is only linked to thermal cycling.

The shift in the ferrite peaks positions with temperature enabled to determine the evolution of its lattice parameter with temperature. Its thermal expansion coefficient was thus obtained from both experiments $n^{\circ} 1$ and $n^{\circ} 2$, and the average value was evaluated at $16.10^{-6}{ }^{\circ} \mathrm{C}^{-1}$.

\section{Oxide scale constitution}

Observation of specimen cross-sections on Fig. 4 shows that isothermal oxidation for 50 hours resulted in the formation of oxide nodules whereas cyclic oxidation resulted in the formation of an oxide scale covering the whole specimen surface with an even thickness. However, both oxide scales have the same duplex structure that was characterized by EDS microanalysis profiles which showed that the external part is iron-rich while the internal part is iron- and silicon-rich. Voiding and some cracking are observed in the outer Fe-oxide layer. The graphite nodules observed in the internal oxide layer indicates that the Fe-Si rich oxide layer was inward growing while the outer Fe-oxide was outward growing. The dotted line in each micrograph of Fig. 4 locates the interface between these inner and outer oxide scales. The above observations are consistent with previous works on Si-rich cast irons from Ekström et al. [4] or Tholence et al. [5] and others, but a new feature was evidenced that is the columnar structure at the interface between the matrix and the inner oxide scale. This columnar structure is located in Fig. 4 for the micrographs of the cycled samples, while it is less apparent but still present on the isothermal sample. Such a feature could be seen on a micrograph in a study by Lekakh et al. [21] (their Fig. 10) but was not commented by these authors. It will be further detailed in the next sub-section. 

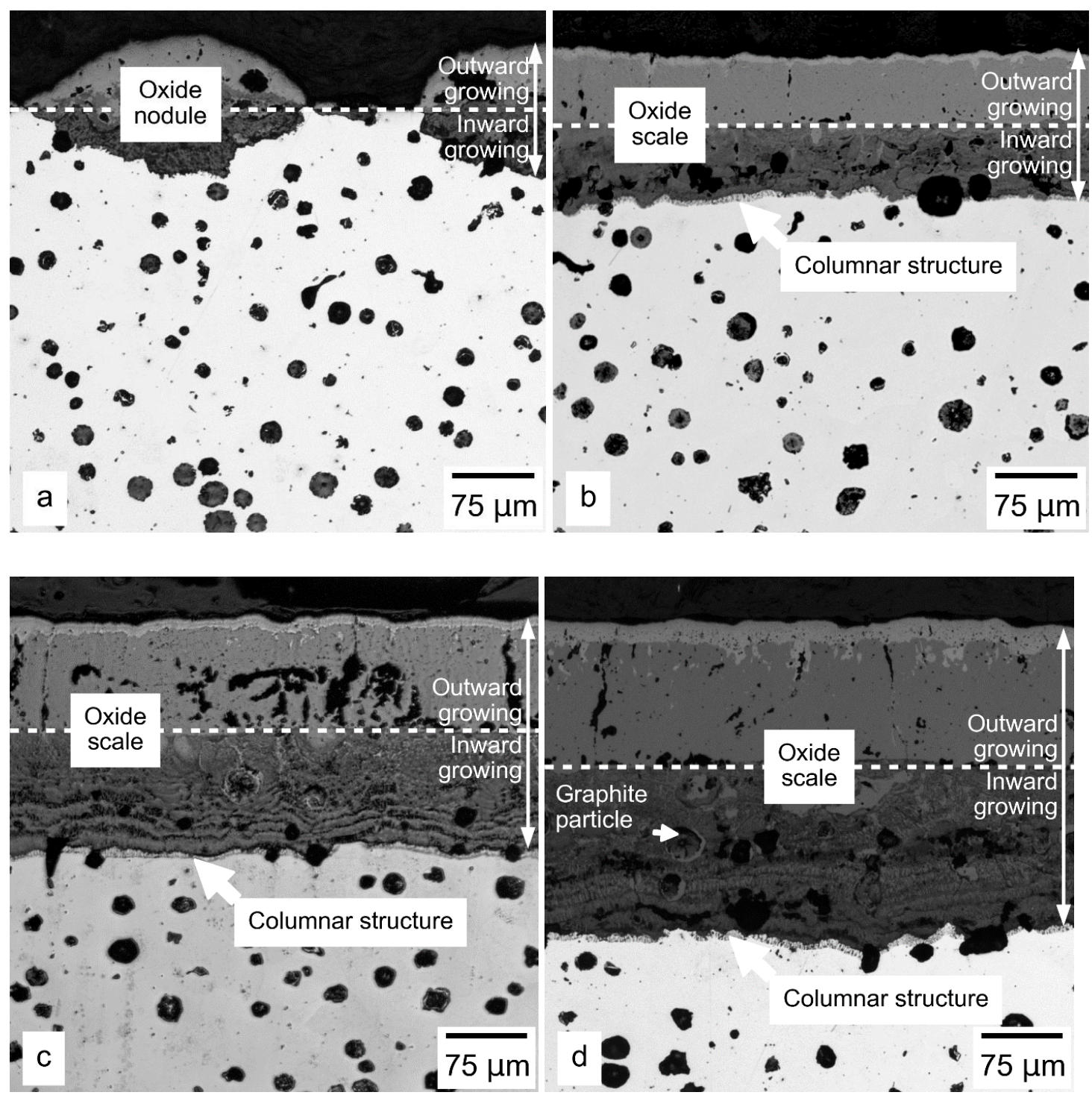

Fig. 4. Optical micrographs of the oxide scale after isothermal holding (a) and 1000 (b), 2000 (c) and 3000 (d) cycles. Dotted lines represent the initial specimen surface and separate the outward growing and inward growing oxide scales.

Raman spectroscopy was used to identify oxides in the scale and in the columnar structure on specimen cross-sections. The Raman spectra obtained after 3000 cycles are presented on Fig. 5. The bands were identified using literature information for fayalite [22] and iron oxides [23]. These spectra reveal that the outward growing iron-rich oxide scale consists of two layers: the thin outermost part of the scale is hematite (point E) while the thicker inner 
part is magnetite (point D). In the inward growing Fe-Si oxide scale, both magnetite and wüstite are detected alongside fayalite (points B and C). At the metal-oxide interface, fayalite is clearly identified (point A) along with other unidentified bands.
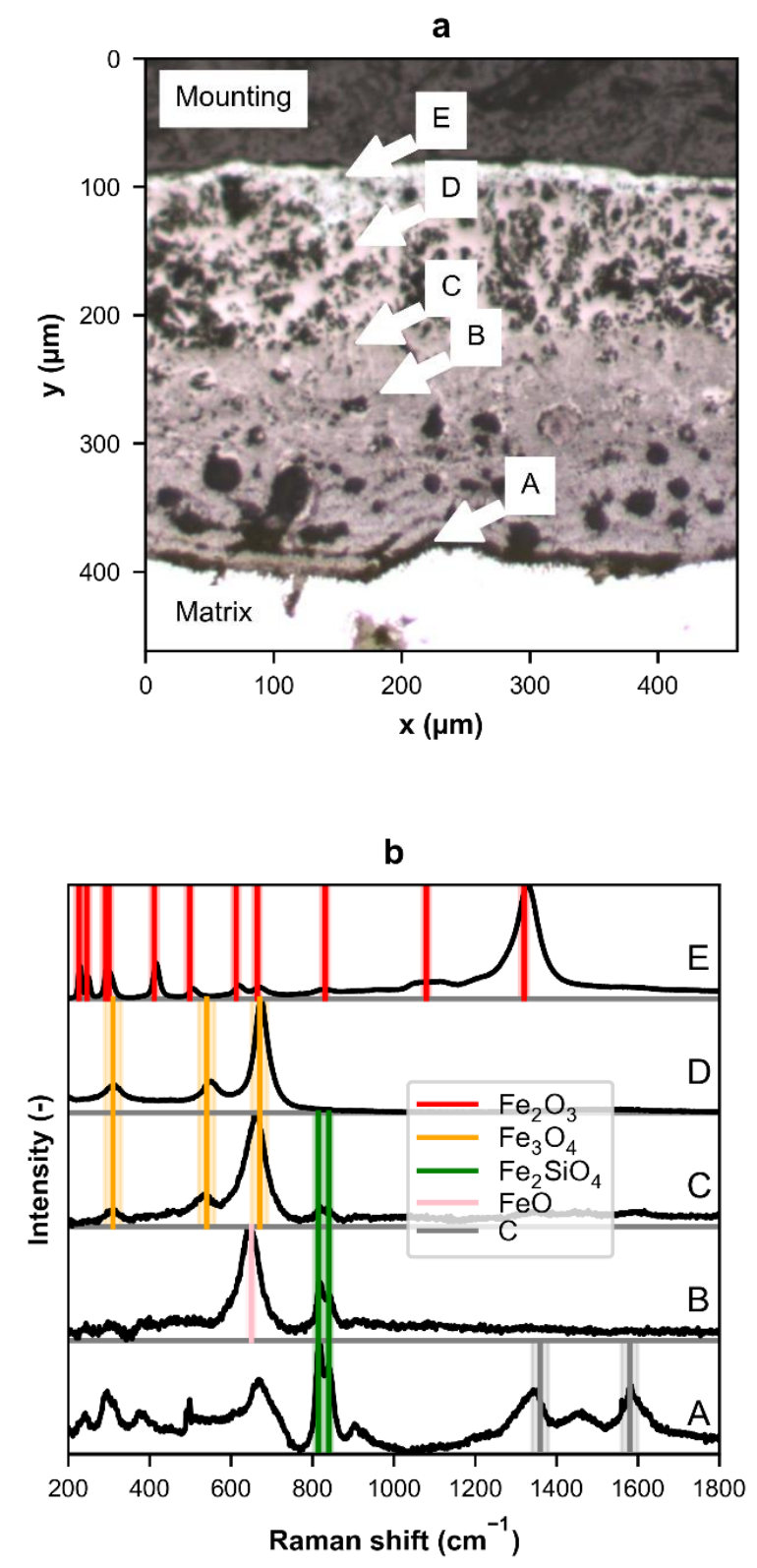

Fig. 5. Light micrograph (a) with the locations of the Raman spectra (b) obtained on the oxide scale cross-section after 3000 cycles. The Raman spectra are labelled according to the locations indicated in a. 
For complementing Raman results, EDS microanalysis maps were recorded on the same sample on the inward growing oxide scale. Fig. 6 shows an example with a SEM image and the corresponding $\mathrm{Si}, \mathrm{Fe}$ and $\mathrm{O}$ mappings. The mappings indicate that the inward growing oxide scale presents three constituents: $\mathrm{Si}$ and 0 -rich areas that could be silica (1); Fe, Si and O-rich areas that could be fayalite (2); O-poor, Si-poor and Fe-rich areas that could be wüstite or magnetite (3).
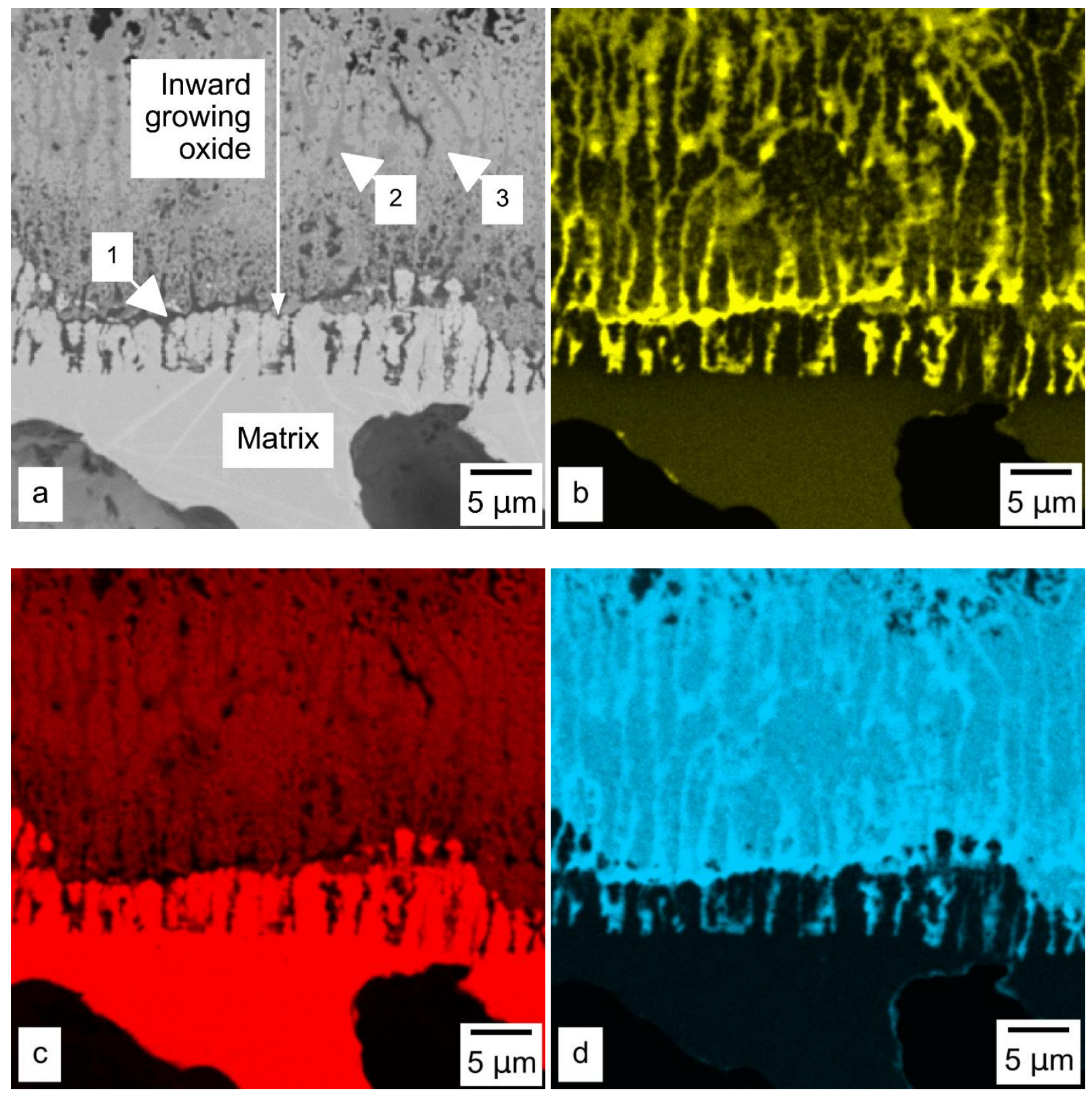
Fig. 6. Characterization of the metal-oxide interface after 3000 cycles: SEM backscattered electron image (a), Si EDS map (b), Fe EDS map (c) and O EDS map (d). 1, 2, 3 denote the different constituents of the inward growing oxide.

\section{The columnar structure}

It should be noted that the above-mentioned columnar area is clearly apparent in both the SEM and mapping images of Fig. 6. It is seen that protrusions of oxide grow inward at the metal oxide interface, and they were observed after both isothermal heat treatment and thermal cycling. After isothermal oxidation, these oxide protrusions are however only clearly apparent at the metal-oxide interface of some of the iron-rich oxide nodules as illustrated with Fig. 7. Because these are the areas where the formation of austenite evidenced by in-situ HT-XRD is expected, EDS microanalysis was carried out to check for local changes in substrate composition. Using EDS line profiles (not shown), a gradient in chemical composition of the matrix was measured over approximately 5 microns below the metal-oxide interface, i.e., twice as much as the length of the protrusions. While the $\mathrm{Si}$ content of the matrix in the bulk is $4.2 \pm 0.1 \mathrm{wt} . \% \mathrm{Si}(7.9 \pm 0.2 \mathrm{at} . \% \mathrm{Si})$, the Si content at the metal-oxide interface in between the oxide protrusions is $2.5 \pm 0.3 \mathrm{wt} . \% \mathrm{Si}$ ( $4.8 \pm 0.7$ at.\% Si). It will be seen in the discussion section that such silicon depletion does favour the formation of austenite at $800^{\circ} \mathrm{C}$.

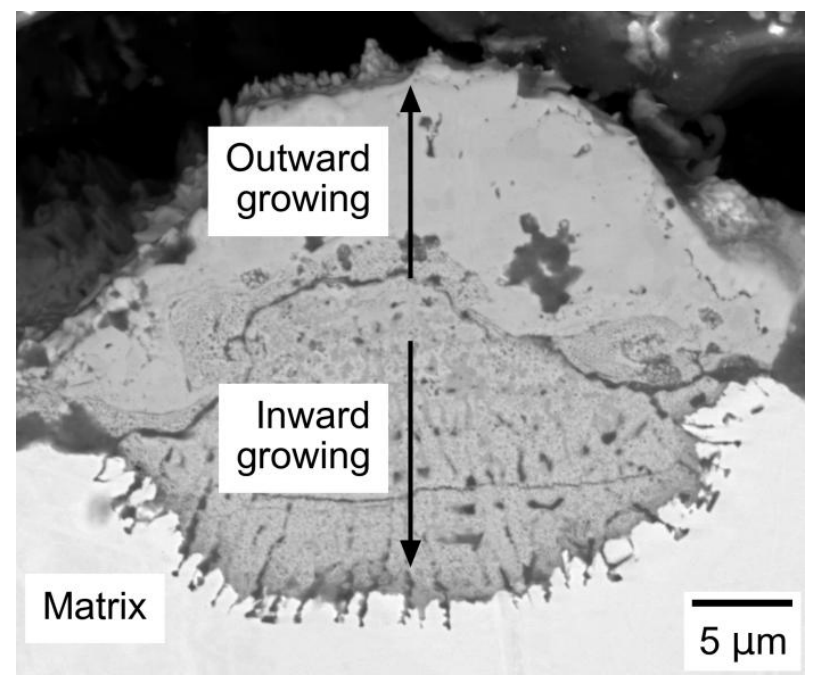


Fig. 7. Back scattered electron image of an oxide nodule after 50 hours at $800^{\circ} \mathrm{C}$.

After cyclic oxidation, the oxide protrusions formed a regular cell-like columnar structure that was observed along most of the metal-oxide interface. Fig. 8 offers a closer look at the metal-oxide interface after thermal cycling. As the protrusions show different grey levels, there may be different oxides in their structure and silicon-rich precipitates are observed in the matrix in between them. The spacing between these protrusions is typically 2-3 microns and does not seem to be affected by the number of thermal cycles, while the thickness of the columnar structure increases slightly with the number of thermal cycles as can be seen in Fig. 4. It is also noted in Fig. 8-a that ghosts of this columnar zone form layers within the inner oxide scale.

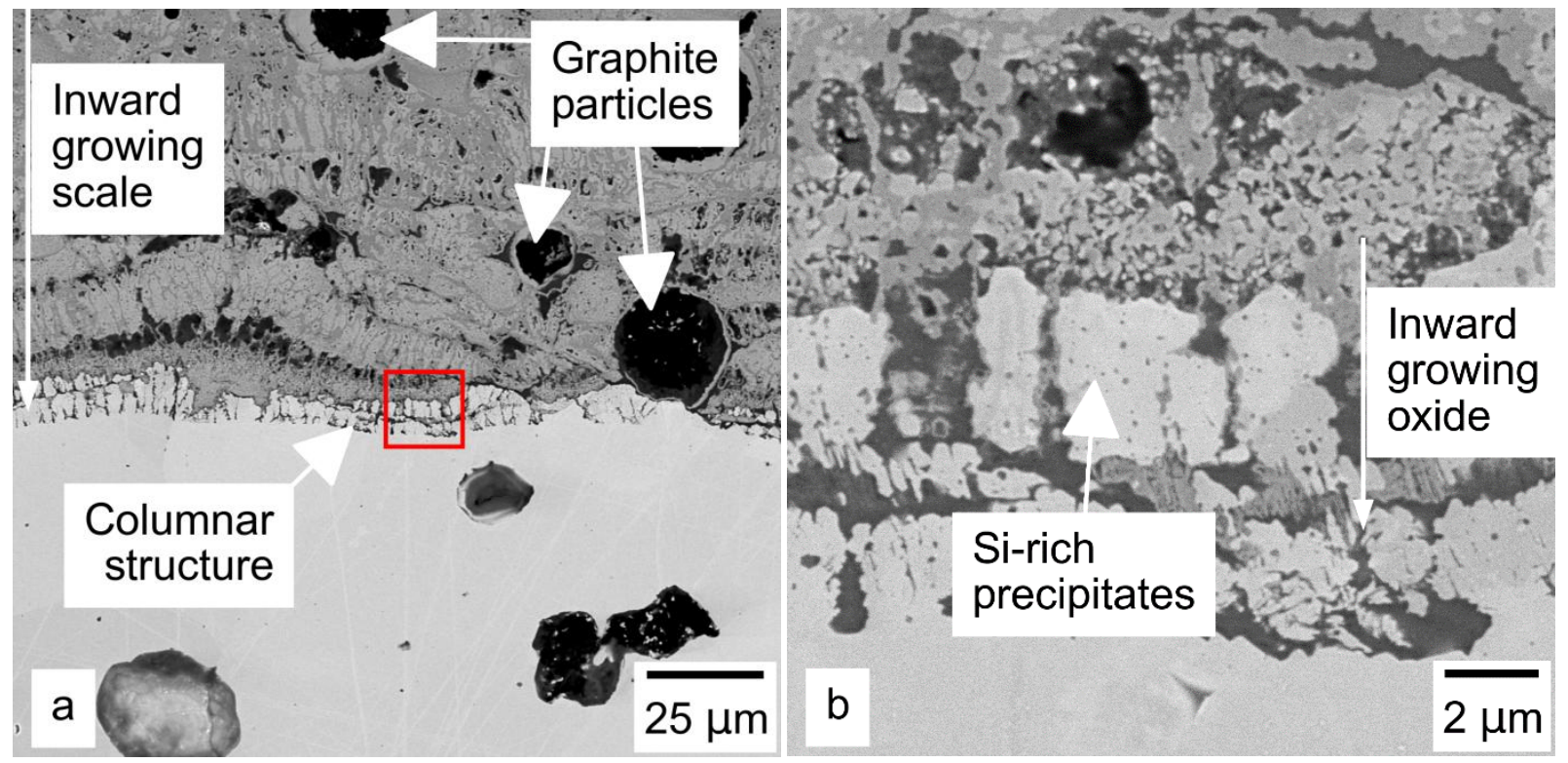

Fig. 8. Back scattered electron image of the oxide scale after 3000 cycles: inward growing oxide scale (a) and columnar structure at metal-oxide interface (b). The micrograph in b is a close up of the squared area in a.

In an attempt to identify the phases in the columnar structure, a Raman mapping at high magnification was recorded that is displayed on Fig. 9. Iron oxide is detected in the metallic 
matrix at the tip of some but not all of the oxide protrusions. In between the protrusion tips and the inner oxide scale, fayalite was also detected, either alone or with iron oxide. Due to poor signal in this area, this iron oxide could not be properly identified with Raman spectroscopy. Indeed, the peak related to the red colour on the mapping is in the range 640 - $670 \mathrm{~cm}^{-1}$ and can be attributed to either wüstite or magnetite [24]. Accordingly, this iron oxide is thus denoted $\mathrm{Fe}_{x} \mathrm{O}_{y}$ in Fig. 9. Note that, however, only wüstite is theoretically expected at the metal-oxide interface at $800^{\circ} \mathrm{C}$.

In a previous work on Hi-Si SGI, magnetite and fayalite were identified using both Raman spectroscopy and XRD after grinding the surface to remove the outer scale [12]. Using the same grinding technique, wüstite was clearly identified from XRD patterns along with fayalite by Méndez et al. [6]. It is worth noting that wüstite is observed deeper in the scale than magnetite, which could explain why it was not reported in some other previous works on Hi-Si SGI if the grinding was not prolonged enough.

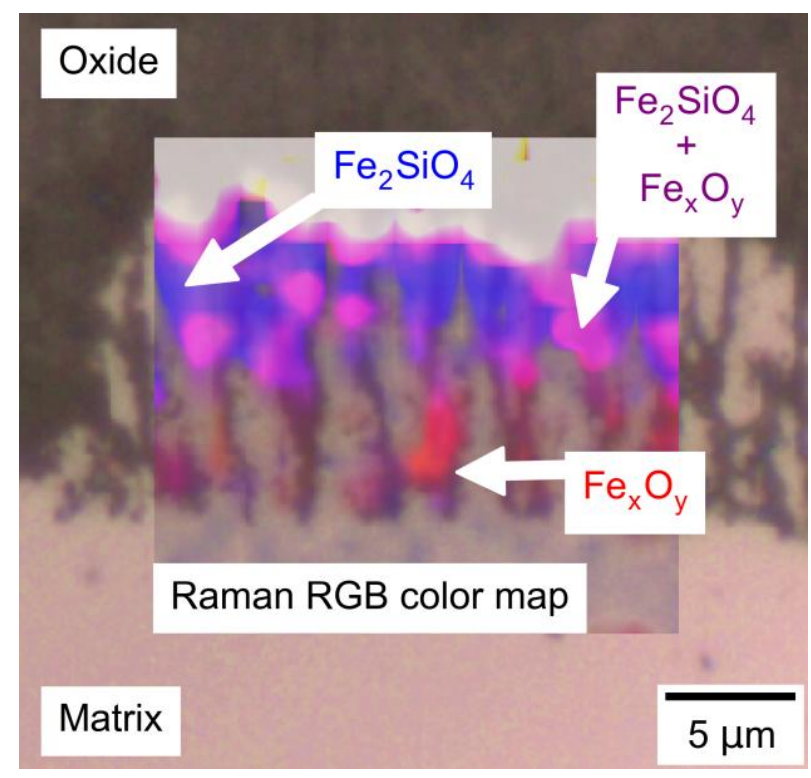

Fig. 9. Raman map obtained at the metal-oxide interface after 3000 cycles: iron oxide $\mathrm{Fe}_{\mathrm{x}} \mathrm{O}_{\mathrm{y}}$ is red (see text), fayalite $\mathrm{Fe}_{2} \mathrm{SiO}_{4}$ is blue, pink areas contain both iron oxide and fayalite. 
EDS mappings of Fig. 6 showed that the oxide protrusions in the columnar structure are mainly Si-rich with some parts containing little iron. This result is consistent with the identification of fayalite and iron oxide on the Raman mapping. The EDS mappings also show that the tips of the oxide protrusions where no oxide could be identified on Raman spectra are mainly silicon rich and therefore could be amorphous silica. As a matter of fact, transmission electron microscopy (TEM) is needed to clearly identify silica [11] which was not attempted in the present study.

Finally, and as already noted for the isothermal sample, EDS point analysis in the matrix located between the oxide protrusions of the columnar structure showed silicon depletion compared to the matrix located further in the substrate.

\section{Evaluation of oxidation and decarburization kinetics}

As described in the Materials and Methods section, the samples were removed from the test rig every 200 cycles to be weighted. No debris from oxide spallation could be observed during thermal cycling and the oxide scale remained adherent during all handling operations. It is therefore assumed that the oxide scale remained adherent during the whole experiment and that oxide spallation was negligible.

Weight monitoring performed during the thermal cycling experiment is presented on Fig. 10-a. As expected, it shows clearly that the specific mass change, denoted apparent specific mass change $\Delta m_{\text {app }} / S$, increased with the number of cycles due to the formation of oxide scale. In this graph, the bars represent the scattering of the measurements which were performed on 9 samples for up to 1000 cycles, 6 samples between 1200 and 2000 cycles and finally 3 samples for the remaining cycles. The scattering increased because of this decreasing number of data and certainly also because of differences in the overall oxidation kinetics between samples. The apparent specific mass gain for the isothermal sample is also shown in Figure 10-a for comparison with the results at 3000 cycles.

The oxide scale thickness was measured in several locations after 1000, 2000 and 3000 thermal cycles, and after isothermal oxidation. As the oxide scales showed an even 
thickness after thermal cycling, the thickness measurements reported on Fig. 10-b are related to the overall oxide scale thickness. On the contrary, for the isothermal heat-treated specimen, oxide thickness measurements were only performed on oxide nodules. During cross-section preparation of this latter specimen, the oxide scale heavily spalled so that the number of measurements was limited. Therefore, the thickness of the oxide nodules shown in Fig. 10-b for the isothermal sample may be more indicative than statistically relevant. It is noted however that this value of $130 \mu \mathrm{m}$ is of the same order than the $150 \mu \mathrm{m}$ obtained by Lekakh et al. on a Hi-Si SGI with similar silicon content (4.2 wt.\%) oxidized in the same conditions (temperature, atmosphere) but for a longer time of $100 \mathrm{~h} \mathrm{[10].} \mathrm{We} \mathrm{will} \mathrm{come}$ back to this difference later.

Comparison of the specific mass variation and of the thickness of the oxide scale resulting from thermal cycling and isothermal oxidation on Fig. 10 show large differences. The oxide scale measured after 3000 thermal cycles is approximatively twice thicker than the oxide nodules resulting from isothermal oxidation. Such a difference can be clearly seen with the micrographs in Fig. 4. As a result, Fig. 10-a shows that the change in apparent specific mass after 3000 short thermal cycles is approximately twice as high as after isothermal oxidation.
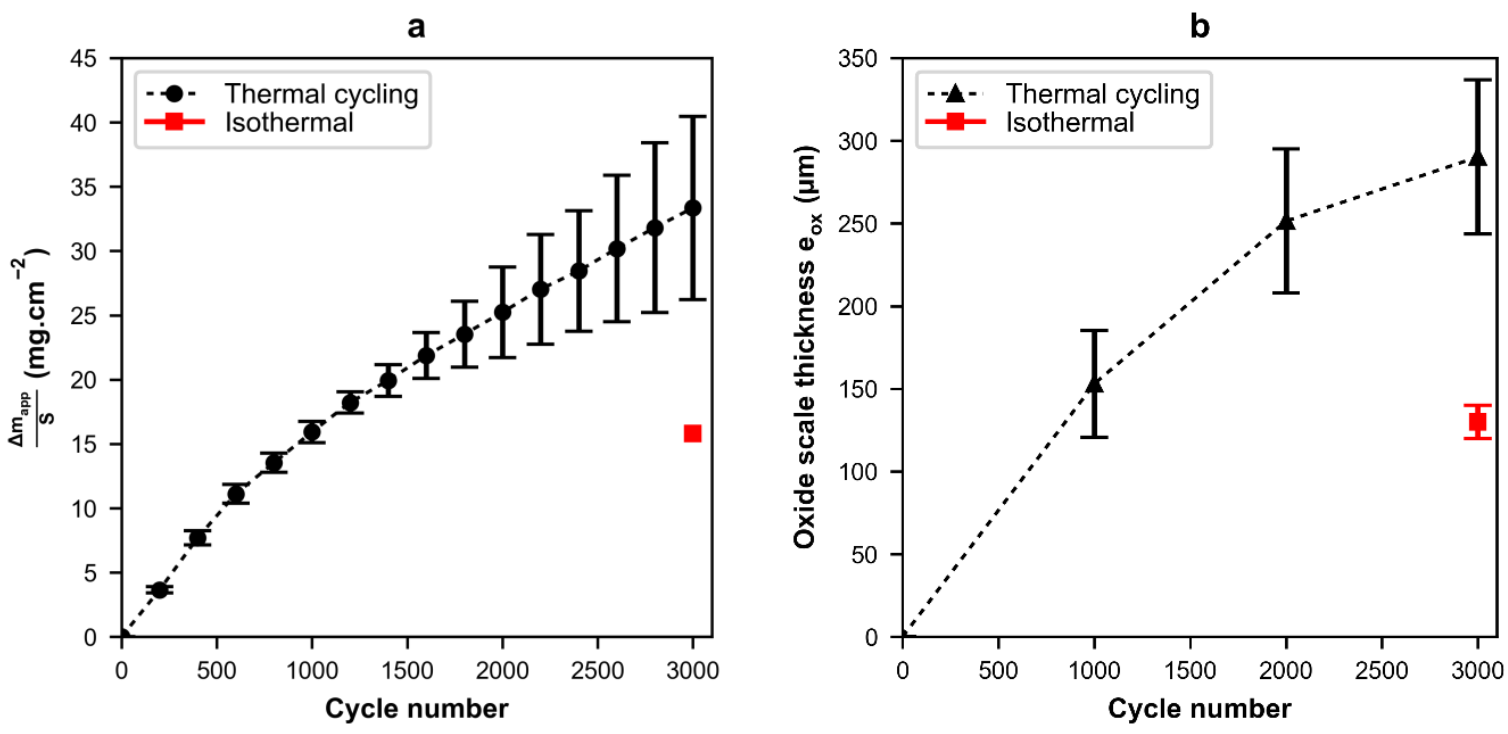
Fig. 10. Evolution of the apparent specific mass (a) and total oxide scale thickness (b) during cyclic oxidation. The specific mass variation and oxide thickness resulting from the $50 \mathrm{~h}$ isothermal heat-treatment are reported at 3000 cycles for comparison purpose. Points are related to mean values of measurements while the height of the error bars is twice the standard deviation of the related measurements.

The apparent specific mass variation $\Delta m_{a p p} / S$ obtained through weight measurements is not a good metric for oxidation of SGI at $800^{\circ} \mathrm{C}$ because it is the sum of the specific mass gain due to oxide formation $\Delta m_{o x} / S$ and the specific mass loss due to decarburization $\Delta m_{C} / S:$

$\frac{\Delta m_{a p p}}{S}=\frac{\Delta m_{o x}}{S}+\frac{\Delta m_{C}}{S}$

Oxide scale thickness $e_{o x}$ is a more suitable metric if the thickness of the oxide scale formed is even over the whole specimen surface as is the case for the experiments with thermal cycling. Assuming oxidation kinetics follows a parabolic rate with a constant $k_{p}^{o x}$ that depends on the temperature $\mathrm{T}$ and is constant over time $\mathrm{t}$ for a given temperature, the change in oxide scale thickness $e_{o x}$ can be expressed as [25]:

$\frac{d e_{o x}(T(t))}{d t}=\frac{k_{p}^{o x}(T(t))}{e_{o x}(T(t))}$

In case of thermal cycling, the thickness $e_{o x}^{\text {cycle }}$ of the oxide scale grown during one thermal cycle of duration $t_{\text {cycle }}$ is thus obtained by time integrating Eq. (2). This leads to:

$e_{o x}^{c y c l e}=\int_{0}^{t_{c y c l e}} \frac{d e_{o x}(T(t))}{d t} d t=\int_{0}^{t} c y c l e \frac{k_{p}^{o x}(T(t))}{e_{o x}(T(t))} d t$

It will be further assumed that the parabolic oxidation rate follows an Arrhenius law which is written:

$k_{p}^{o x}(T(t))=A_{0} e^{\frac{-E_{a}}{R \cdot T(t)}}$ 
For calculations, each thermal cycle was discretized into $\mathrm{n}$ time steps. Using $\mathrm{i}$ as the increment for time within a thermal cycle and $\mathrm{j}$ as the increment for the number of thermal cycles, the oxide scale thickness can be defined as:

$e_{o x}\left(t=t_{i}\right.$, cycle $\left.=j\right)=e_{i}^{j}=e_{i-1}^{j}+\frac{k_{p}^{o x}\left(T\left(t_{i}\right)\right)}{e_{i-1}^{j}} \Delta t$

For any thermal cycle $\mathrm{j}$, the initial oxide scale at $\mathrm{t}=0(\mathrm{i}=0)$ is set to the oxide scale computed at the end $(i=n)$ of the previous cycle $(j-1)$, i.e.:

$e_{0}^{j}=e_{n}^{j-1}$

For the first cycle, the initial oxide scale thickness $e_{0}^{0}$ was arbitrarily set to $100 \mathrm{~nm}$. Using the experimental thermal cycles for describing the change $T(t)$, the oxide thickness could then be calculated as a function of the number of thermal cycles for any activation energy $E_{a}$ and any pre-exponential term $A_{0}$ of the Arrhenius law describing the oxidation kinetics. A minimization procedure was applied to determine the parameters $A_{0}$ and $E_{a}$ for which the calculated oxide thickness has the best fit with the oxide thickness measured after 1000, 2000 and 3000 thermal cycles. The result of the minimization procedure gave $A_{0}=5.96 \cdot 10^{-6}$ $\mathrm{m}^{2} \cdot \mathrm{s}^{-1}$ and $\mathrm{E}_{\mathrm{a}}=1.58 \cdot 10^{5} \mathrm{~J} \cdot \mathrm{mol}^{-1}$. With these values, it is seen in Fig. 11 that the calculated thickness values are in good agreement with experimental results. Interestingly, the calculation for isothermal conditions also led to a good agreement with the experimental value as shown in Fig. 11. This suggests that the increased oxidation during thermal cycling as compared to isothermal condition is mostly due to the heating and cooling stages and not to a change in the oxidation mechanism. 


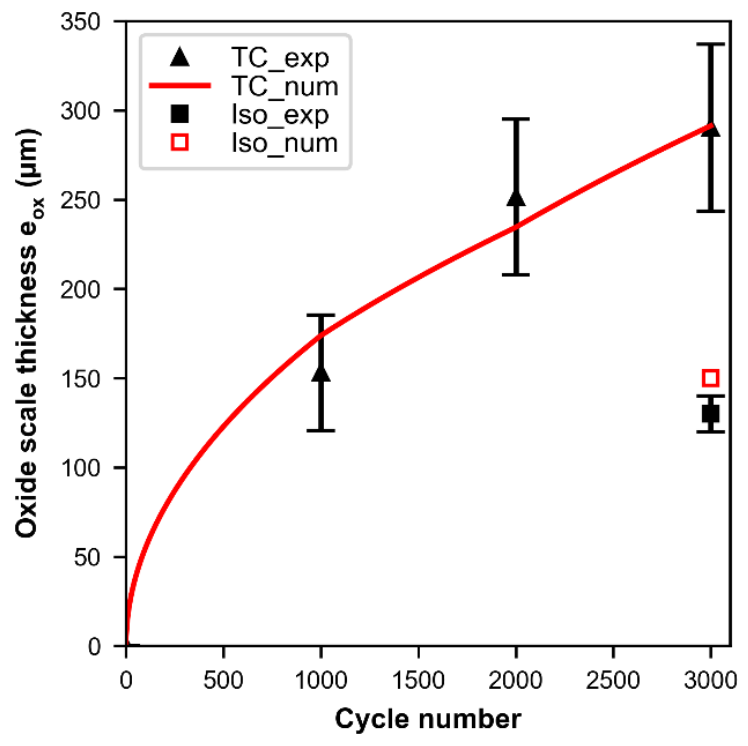

Fig. 11. Comparison of the experimental oxide scale thickness measured during thermal cycling (TC_exp) and isothermal heat-treatment (Iso_exp) with the results from the oxidation model for thermal cycling (TC_num) and isothermal heat-treatment (Iso_num).

The Arrhenius law that has been identified for the parabolic oxidation rate can be discussed by comparison with literature data for silicon [26] and for iron [27] isothermal oxidation that are indicated along the corresponding lines in Fig. 12. This figure shows that the present estimate for Hi-Si SGI is quite close to that for pure iron oxidation, with a slower value that can probably be associated to some positive effect of silicon. However, the present analysis does not show an effect of the formation of silica in slowing down the oxidation kinetics between 700 and $800^{\circ} \mathrm{C}$, in line with the presence of water in air and possibly also because of the detrimental effect of the columnar zone. 


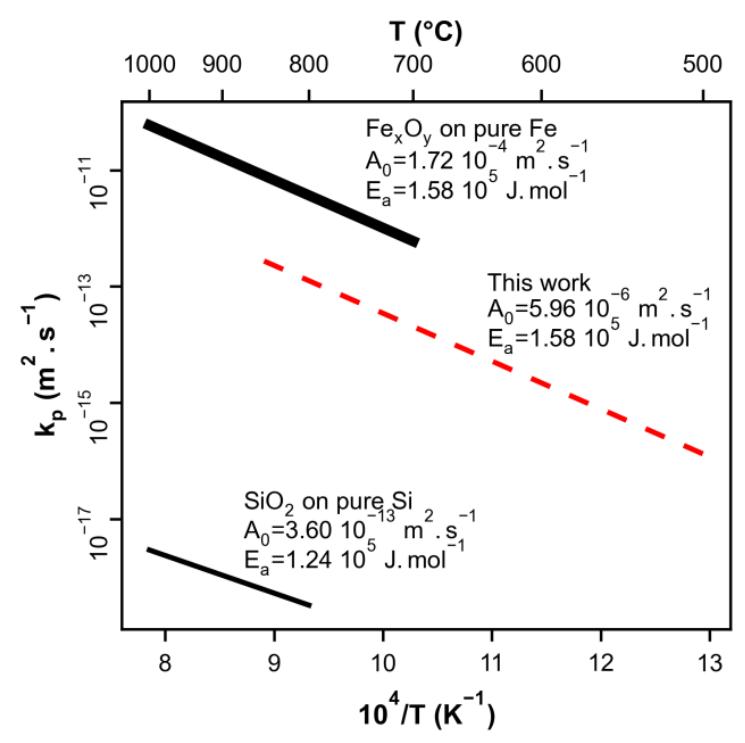

Fig. 12. Comparison of the parabolic rate of formation of silica on Si, iron oxides on Fe and the oxide scale formed on Hi-Si SGI in this work.

Using again the fact that the oxide layer has even thickness during cyclic oxidation, the specific mass gain due to oxidation can be derived considering an equivalent oxide layer with a density $\rho_{o x}$, a molar mass $M_{o x}$ and a number of moles of oxygen, $\gamma_{o x}$, per mole of oxide. With $M_{O}$ being the molar mass of oxygen, the specific mass gain due to oxidation is given as:

$\frac{\Delta m_{o x}}{S}=e_{o x} \frac{\gamma_{o x} \rho_{o x}}{M_{o x}} M_{O}$

The molar volume of the oxide scale can be derived from the thickness of base metal consumed through the oxidation process $e_{\text {con }}$ considering it relates to the thickness of the inward growing scale. With $V_{M}, M_{M}$ and $\rho_{M}$ being the molar volume, the molar mass and density of the matrix, respectively, the equivalent molar volume of the oxide $V_{\text {ox }}$ can be determined from the following balance:

$e_{c o n}=\left(\frac{M_{M}}{\rho_{M}} \frac{\rho_{o x}}{M_{\mathrm{ox}}}\right) e_{o x}=\left(\frac{V_{M}}{V_{o x}}\right) e_{o x}$ 
For calculations, the molar volume of the Fe-Si matrix was evaluated using the density value of $7.570 \mathrm{~g} \cdot \mathrm{cm}^{-3}$ that was previously estimated [16]. The molar mass was set to $53.5 \mathrm{~g} \cdot \mathrm{mol}^{-1}$ considering a binary Fe-Si alloy with 4.45 wt.\% Si. The molar volume of the oxide offering the best fit with the data was obtained using the molar mass and density of wüstite, respectively $71.8 \mathrm{~g} \cdot \mathrm{mol}^{-1}$ and $5.7 \mathrm{~g} \cdot \mathrm{cm}^{-3}$. Inserting this data in Eq. (7) and using the average experimental thickness measurements plotted on Fig. 11, the specific mass variation due to oxidation was computed for 1000, 2000 and 3000 cycles and is plotted with upwards triangles in Fig. 13. It is seen that these estimates are higher than the measured apparent specific mass values, which suggests that the mass loss due to decarburization, $\Delta m_{C}$, cannot be neglected. Based on Eq. (1), this mass loss is such that $\frac{\Delta m_{C}}{\mathrm{~S}}=\frac{\Delta m_{a p p}}{\mathrm{~S}}-\frac{\Delta m_{o x}}{\mathrm{~S}}$ and its estimates are plotted with downwards triangles in Fig. 13. The mass loss due to decarburization evaluated in this way appears more or less constant at $-5 \mathrm{mg} \cdot \mathrm{cm}^{-2}$, a value that was reached during the first 1000 cycles.

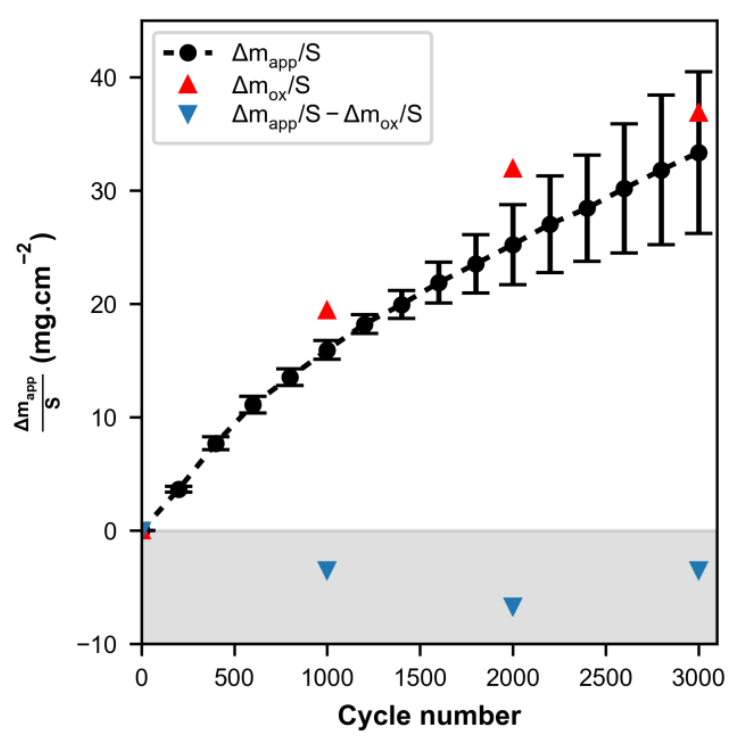

Fig. 13. Comparison of the experimental apparent specific mass with the calculated specific mass resulting from oxidation and the mass loss from decarburization. 
This mass loss should be linked to the decarburized depth $e_{d e c}$ of the substrate below the original matrix surface, the graphite fraction in the matrix $f_{C}$ and the graphite density $\rho_{C}$ by the following relation:

$\frac{\Delta m_{C}}{S}=e_{d e c} f_{C} \rho_{C}$

The decarburization depth thus calculated is in the range 150-300 $\mu \mathrm{m}$. Observation of the matrix below the oxide scale on the optical micrographs of Figs. 4-b to 4-d clearly shows that some graphite particles are missing. A closer look at the metal-oxide interface with the greater depth of field provided by SEM observations on Fig. 8 confirms that cavities can be observed at the previous location of graphite particles. Thus, decarburization took place during heat treatment and carbon from the dissolved graphite particles diffused towards the metal-oxide interface and escaped as gaseous species. This process has recently been studied in detail by Lekakh et al. $[10,11]$.

Measuring the distance between the metal-oxide interface and the farthest cavities would quantify the extent of decarburization. However, both cavities resulting from decarburization and apparently intact graphite particles can be observed at similar depth below the oxide-metal interface. This means that graphite particles can dissolve in the matrix at different rates, making it difficult to assess decarburisation using metallographic observations. While the real decarburization depth $e_{\text {dec }}$ could hardly be quantified, the fact that the central part of the studied samples was not decarburized [16] suggests $e_{\text {dec }}$ should be of the same order as the oxide scale, i.e., $150 \mu \mathrm{m}$, for both isothermal and cyclic oxidation. Such a value is much lower than the one observed after $100 \mathrm{~h}$ isothermal oxidation at $800^{\circ} \mathrm{C}$ by Lekakh et al. [11] in which work the decarburized depth was several times thicker than the actual oxide scale. In fact, the present experiments were performed in still air, whereas Lekakh et al. imposed an air flow of $0.5{\mathrm{~L} . \mathrm{min}^{-1}}^{-1}$ to avoid gas starvation. Such conditions may have favored oxidation of carbon and its loss as gas species. Accordingly, less oxygen would have been available for further oxidation of the cast iron matrix which is in accordance with the lower oxidation rates in Lekakh's experiments than in the present ones as noticed above in relation with Fig. 10-b. 


\section{Discussion}

The oxide scales observed in this work after isothermal holding at $800^{\circ} \mathrm{C}$ and thermal cycling show the same duplex structure, and their growth kinetics could be described with the same parabolic law. In agreement with literature, the continuous and even scale observed after thermal cycling results from lateral growth of oxide nodules until they coalesce. From the results described above, it can be concluded that the highlighted columnar structure is important in the oxidation mechanism of Hi-Si SGI. This discussion is thus intended to elaborate on the origin of this structure and the probable coupled effect of iron oxide growth, silica formation, carbon and silicon redistribution, as well as austenite formation.

Atkinson and Gardner [28] have described the formation of silica during oxidation of Fe-Si alloys as resulting from silicon being rejected in front of the iron oxide nodules growing inward as silicon cannot enter into iron oxides. The silicon content in the matrix in contact with the Fe-rich oxide scale thus increases until it becomes high enough for silica to precipitate, which then forms a protective layer. In the case of cast irons, the silica layer is certainly effective in slightly slowing down oxidation kinetics but it gets easily disrupted and overtaken by the fast growing iron oxide nodules. When this happens, silica should react with wüstite to form fayalite because it is impossible for silica, wüstite and the matrix to be in equilibrium at a single oxygen pressure for a given temperature.

A key result of the in-situ HT-XRD experiments performed in this work is the detection of the phase transformation of the ferritic matrix into austenite close to the specimen surface at $800^{\circ} \mathrm{C}$. Differential thermal analysis performed on the same alloy demonstrated that the phase transformation of ferrite does not take place below $860^{\circ} \mathrm{C}$ for the bulk material [16]. Austenite formation during oxidation is thus guessed to be associated with the silicon depletion of the matrix due to the formation of silica that has already been described in the literature for Fe-Si model alloys [29]. On the calculated isotherm section of the relevant phase diagram in Fig. 14, it is seen that austenite could appear at $800^{\circ} \mathrm{C}$ provided the local silicon content decreases below about 3 wt.\%. The extremities of the arrow in Fig. 14 
correspond to the composition of ferrite far from the oxide scale, namely $4.45 \mathrm{wt} . \% \mathrm{Si}$, and to the average EDS measurement at the metal oxide interface at $2.5 \mathrm{wt} . \%$ Si that was reported above. This shows effectively that austenite could have formed during both isothermal and cyclic oxidation when the temperature reaches $800^{\circ} \mathrm{C}$.

However, silicon depletion is not the only condition for austenite to form at $800^{\circ} \mathrm{C}$. As shown with Fig. 14, austenite requires carbon for growing. As the solubility of carbon in ferrite is negligible, the carbon required for austenite to grow can only come from graphite. In other words, growth of austenite in the silicon depleted ferritic matrix is also controlled by carbon diffusion from graphite to the surface through the ferritic matrix. The carbon that is thus temporarily fixed by the austenite does not escape as gaseous species, which may explain the lower decarburisation observed in the present work compared to the results reported by Lekakh et al. In turn, if the conditions are such that most of the carbon escapes as gas, austenite cannot form as easily and this could explain why the columnar structure was not observed in previous works. It seems therefore that the experimental conditions selected in the present work were particularly appropriate to highlight the mechanism by which the columnar structure appears, and that this mechanism must be related to the formation of austenite.

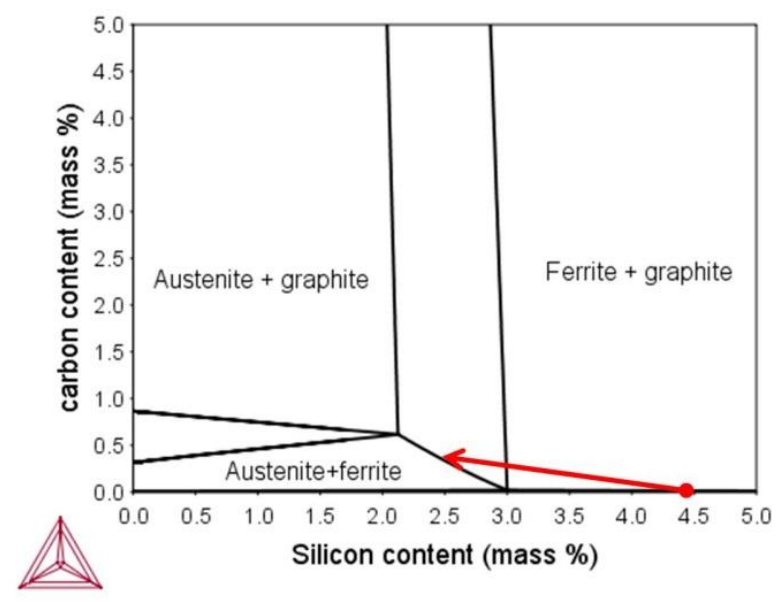

Fig. 14. Isothermal $800^{\circ} \mathrm{C}$ section of the Fe-C-Si-Mn phase diagram with $0.25 \mathrm{wt} . \% \mathrm{Mn}$ showing that only ferrite is stable for Si contents higher than $3 \mathrm{wt} . \%$ and that austenite appears for lower Si contents. The calculations were made with the Thermocalc software 
and the TCFE8 database [30]. The red arrow illustrates the change of composition from the bulk ferrite to the area in between oxide protrusions.

From the above discussion, a schematic for the formation and development of the complex oxide scales that have been observed may be proposed. During early oxidation, iron oxides form on top of a thin silica layer while a silicon gradient develops in the substrate as illustrated with the graded contrast in the scheme of Fig. 15-a. When the sample is heated to $800^{\circ} \mathrm{C}$, small austenite grains eventually nucleate and develop at the interface between the matrix and the silica layer. As austenite grows, it contracts with respect to ferrite and this gives rise to stresses exerted on the silica layer which are illustrated with the solid arrows in Fig. 15-b. Such stresses lead eventually to ruptures in the silica layer shown with thick vertical dark lines, and to stress release in both phases. Through these cracks, the iron oxide may rapidly overtake the original silica layer, pushing away and alongside particles of silica. During this stage, the silica layer transforms in a mix of fayalite and iron oxides (see Fig. 15c), and carbon is rejected on the side of the protrusions where it further stabilizes austenite.

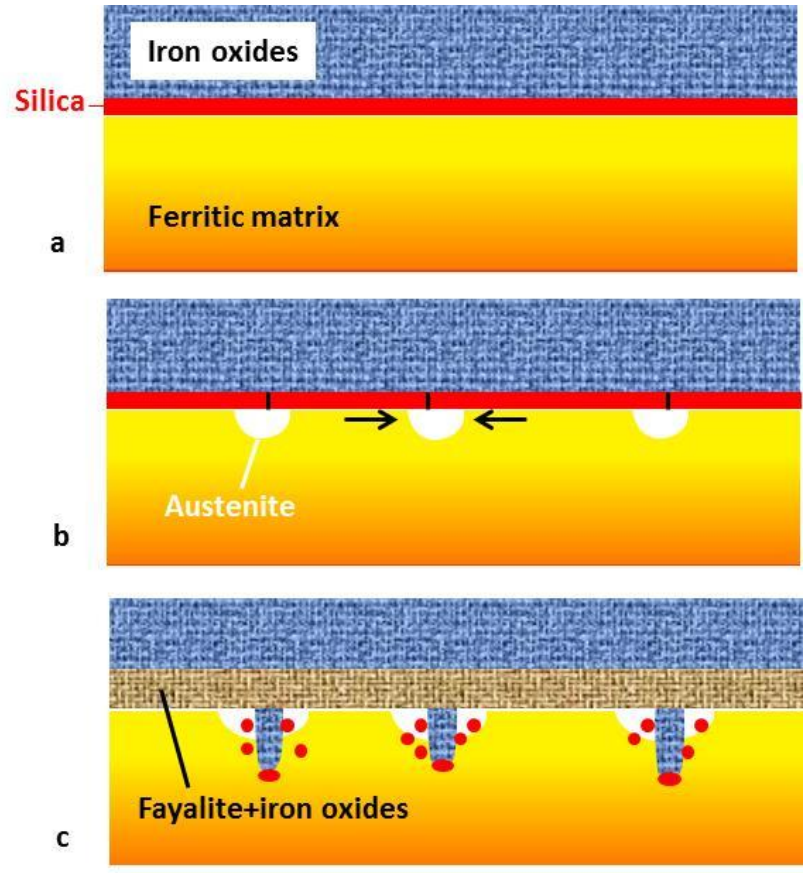

Fig. 15. Schematic diagram showing the formation of protrusions of iron oxides along the interface between the cast iron substrate and the inner oxide layer during oxidation at $800^{\circ} \mathrm{C}$. 
Once the silica layer at the interface between the substrate and the internal iron oxide scale has completely transformed into $\mathrm{Fe}_{\mathrm{x}} \mathrm{O}_{\mathrm{y}}$ and fayalite, fayalite stops growing. At this point, the process of silica layer formation at the metal/oxide interface can start again until the formation of austenite leads to its cracking here and there. The fact that this is a repetitive process is demonstrated by Figure 16, where it can be seen that the columnar zone is not continuous along the boundary between the matrix and the inner oxide layer, as well as by the clearly separated columnar-type layers in the inner oxide layer. Furthermore, the observation that the thickness of the columnar structure increases with cycling is certainly in line with the fact that these protrusions are so little developed in the isothermally oxidised sample. However, further work seems necessary to clarify whether the effect of cycling is due to stress accumulation, increased silicon consumption or austenite formation, or else a coupling of these phenomena with temporary carbon fixing.

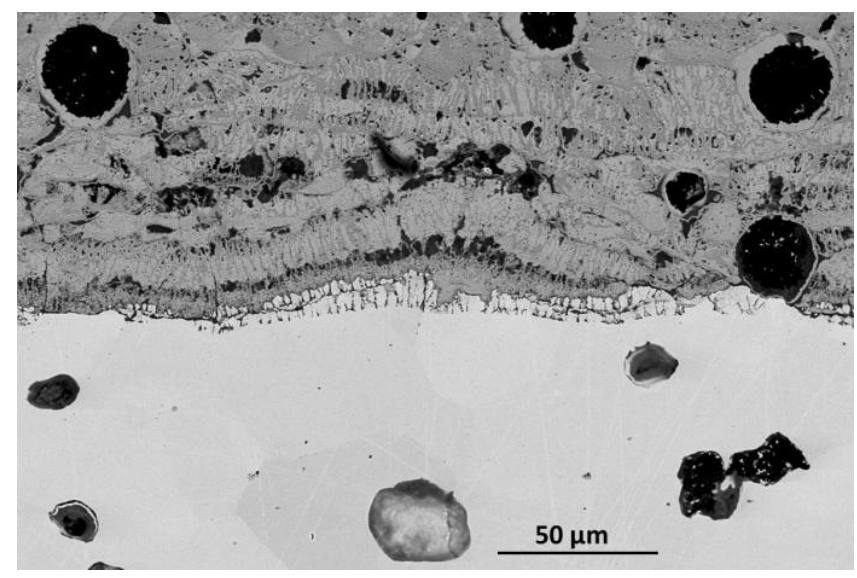

Fig. 16. SEM micrograph of a sample having been cycled 3000 times showing the disruption of the columnar zone and its ghosts within the inner oxide scale.

\section{Conclusion}

To test the high silicon cast iron used for automotive exhaust manifolds, rapid thermal cycling oxidation up to $800^{\circ} \mathrm{C}$ was performed and compared to a reference sample oxidised at constant temperature. Optical observations, micro-analyses and Raman spectroscopy 
showed that the outer and inner oxide layers have the same constituents in cyclic and isothermal oxidation. The experimental cyclic oxidation kinetics could be described by considering an equivalent oxide layer following a parabolic growth law which was found to apply also to the isothermal oxidation test. It could thus be concluded that the oxidation mechanism is the same under both conditions.

However, the rapid cyclic oxidation favours the formation of a columnar zone at the substrate/oxide interface which has never been reported but could also be observed to a small extent on the isothermal sample. In addition, in-situ high-temperature X-ray diffraction showed the formation of austenite at $800^{\circ} \mathrm{C}$ associated with silicon depletion at the substrate surface due to the precipitation of silica, which then transforms into fayalite. This results in the repetitive formation of successive layers, the remnants of which appear in the inner oxide scale. A probable mechanism for this repetitive process has been proposed, which is based on the formation of silica, its mechanical breakdown due to the precipitation of austenite, followed by an overgrowth of rapidly growing iron oxides. This process is also thought to occur during isothermal oxidation, but is highlighted by cycling.

\section{Funding}

None

\section{Acknowledgments}

Azterlan (Bizkaia) kindly provided the material used in this study. Special thanks are due to Yannick Thebault for SEM observations and EDS measurements. The quality of the experimental work performed by Mariana Alves Pegoraro during her stay at CIRIMAT is greatly acknowledged as well as the support of Ronan Mainguy.

\section{Data availability}


The raw/processed data required to reproduce these findings cannot be shared at this time due to technical or time limitations

\section{References}

[1] C. Labrecque, M. Gagné, Ductile iron: Fifty years of continuous development, Canadian Metallurgical Quarterly. 37 (1998) 343-378. https://doi.org/10.1016/S00084433(98)00031-7.

[2] W. Fairhurst, K. Rohrig, High-silicon nodular irons, Foundry Trade Journal. 146 (1979) 657-681.

[3] J. Lacaze, The austenite to pearlite/ferrite transformation, in: ASM Handbook, Vol. 1A, Cast Iron Science and Technology, Materials Park, 2017, pp. 106-113.

[4] M. Ekström, P. Szakalos, S. Jonsson, Influence of $\mathrm{Cr}$ and Ni on high-temperature corrosion behavior of ferritic ductile cast iron in air and exhaust gases, Oxidation of Metals. 80 (2013) 455-466. https://doi.org/10.1007/s11085-013-9389-8.

[5] F. Tholence, M. Norell, High-temperature corrosion of cast irons and cast steels in dry air, Materials Science Forum. 369-372 (2001) 197-204. https://doi.org/10.4028/www.scientific.net/MSF.369-372.197.

[6] S. Méndez, M.Á. Arenas, A. Niklas, R. González, A. Conde, J. Sertucha, J.J. de Damborenea, Effect of silicon and graphite degeneration on high-temperature oxidation of ductile cast irons in open air, Oxidation of Metals. 91 (2019) 225-242. https://doi.org/10.1007/s11085-018-9875-0.

[7] L.L. Liu, Q.Q. Guo, Y. Niu, Transition between different oxidation modes of binary Fe-Si alloys at $600-800^{\circ} \mathrm{C}$ in pure $\mathrm{O}_{2}$, Oxidation of Metals. 79 (2013) 201-224. https://doi.org/10.1007/s11085-012-9318-2.

[8] A. Atkinson, J.W. Gardner, The diffusion of $\mathrm{Fe} 3+$ in amorphous $\mathrm{SiO}_{2}$ and the protective properties of $\mathrm{SiO}_{2}$ layers, Corrosion Science. 21 (1981) 49-58.

https://doi.org/10.1016/0010-938X(81)90063-9. 
[9] I. Svedung, N.G. Vannerberg, The influence of silicon on the oxidation properties of iron, Corrosion Science. 14 (1974) 391-399. https://doi.org/10.1016/S0010-938X(74)80032-6.

[10] S.N. Lekakh, W. Tucker, A. Bofah, T. Selly, L. Godlewski, M. Li, Quantitative $\mu$-CT analysis of scale topology formed during oxidation of high SiMo cast iron, Oxidation of Metals. 94 (2020) 251-264. https://doi.org/10.1007/s11085-020-09989-0.

[11] S.N. Lekakh, A. Bofah, W.-T. Chen, L. Godlewski, M. Li, Prevention of high-temperature surface degradation in SiMo cast irons by $\mathrm{Cr}$ and $\mathrm{Al}$ alloying, Metallurgical and Materials Transactions B. 51 (2020) 2542-2554. https://doi.org/10.1007/s11663-020-01975-w. [12] A. Ebel, S.Y. Brou, B. Malard, J. Lacaze, D. Monceau, L. Vaissière, High-temperature oxidation of a high silicon SiMo spheroidal cast iron in air with in situ change in $\mathrm{H}_{2} \mathrm{O}$ content, Materials Science Forum. 925 (2018) 353-360. https://doi.org/10.4028/www.scientific.net/MSF.925.353.

[13] S. Yamada, T. Konno, S. Goto, S. Aso, Y. Komatsu, Some behaviors and characteristics of decarburized layer in spheroidal graphite cast iron, International Journal of the Society of Materials Engineering for Resources. 10 (2002) 88-92. https://doi.org/10.5188/ijsmer.10.88.

[14] P. Bastid, P. Pilvin, C. Grente, E. Andrieu, Microstructural evolution of spheroidal graphite cast iron at high temperature: Consequences on mechanical behaviour, Advanced Materials Research. 4-5 (1997) 139-146. https://doi.org/10.4028/www.scientific.net/AMR.4-5.139.

[15] M.P. Brady, G. Muralidharan, D.N. Leonard, J.A. Haynes, R.G. Weldon, R.D. England, Long-term oxidation of candidate cast iron and stainless steel exhaust system alloys from 650 to $800^{\circ} \mathrm{C}$ in air with water vapor, Oxidation of Metals. 82 (2014) 359-381. https://doi.org/10.1007/s11085-014-9496-1.

[16] A. Ebel, M.A. Pegoraro, B. Malard, C. Tenailleau, J. Lacaze, Coarsening and dendritic instability of spheroidal graphite in high silicon cast iron under thermal cycling in the ferritic domain, Scripta Materialia. 178 (2020) 86-89. https://doi.org/10.1016/j.scriptamat.2019.11.001. 
[17] R. González-Martínez, U. de la Torre, J. Lacaze, J. Sertucha, Effects of high silicon contents on graphite morphology and room temperature mechanical properties of as-cast ferritic ductile cast irons. Part i - microstructure, Materials Science and Engineering: A. 712 (2018) 794-802. https://doi.org/10.1016/j.msea.2017.11.050.

[18] M.A. Pegoraro, C. Tenailleau, A. Ebel, B. Malard, J. Lacaze, Spheroidal graphite coalescence during thermal cycling in the ferritic domain of a high-silicon cast iron studied by optical microscopy and X-ray computed tomography, 2020. Materials Today Communications. 25, 101422. https://doi.org/10.1016/j.mtcomm.2020.101422. [19] A.A. Coelho, TOPAS and TOPAS-academic: An optimization program integrating computer algebra and crystallographic objects written in C++, Journal of Applied Crystallography. 51 (2018) 210-218. https://doi.org/10.1107/S1600576718000183. [20] H.M. Rietveld, A profile refinement method for nuclear and magnetic structures, Journal of Applied Crystallography. 2 (1969) 65-71. https://doi.org/10.1107/S0021889869006558.

[21] S.N. Lekakh, C. Johnson, A. Bofah, L. Godlewski, Mei Li, Improving high-temperature performance of high Si-alloyed ductile iron by altering additions, Inter Metalcast. (2020). https://doi.org/10.1007/s40962-020-00524-0

[22] A. Chopelas, Single crystal Raman spectra of forsterite, fayalite, and monticellite, American Mineralogist. 76 (1991) 1101-1109.

[23] D.L.A. de Faria, S.V. Silva, M.T. de Oliveira, Raman microspectroscopy of some iron oxides and oxyhydroxides, Journal of Raman Spectroscopy. 28 (1997) 873-878. https://doi.org/10.1002/(SICI)1097-4555(199711)28:11<873::AID-JRS177>3.0.C0;2-B.

[24] E. Hazan, Y. Sadia, Y. Gelbstein, Characterization of AISI 4340 corrosion products using Raman spectroscopy, Corrosion Science. 74 (2013) 414-418. https://doi.org/10.1016/j.corsci.2013.05.002.

[25] D.J. Young, High Temperature Oxidation and Corrosion of Metals, Elsevier Science, 2008 
[26] B.E. Deal, A.S. Grove, General relationship for the thermal oxidation of silicon, Journal of Applied Physics. 36 (1965) 3770-3778.

[27] R.Y. Chen, W.Y.D. Yeun, Review of the high-temperature oxidation of iron and carbon steels in air or oxygen, Oxidation of Metals. 59 (2003) 433-468.

https://doi.org/10.1023/A:1023685905159.

[28] A. Atkinson, A theoretical analysis of the oxidation of Fe-Si alloys, Corrosion Science. 22 (1982) 87-102. https://doi.org/10.1016/0010-938X(82)90071-3.

[29] R.C. Logani, W.W. Smeltzer, The development of the wüstite-fayalite scale on an iron1.5 wt. silicon alloy at $1000^{\circ} \mathrm{C}$, Oxidation of Metals. 3 (1971) 15-32. https://doi.org/10.1007/BF00604737.

[30] J.-0. Andersson, T. Helander, L. Höglund, P. Shi, B. Sundman, Thermo-calc \& DICTRA, computational tools for materials science, Calphad. 26 (2002) 273-312. https://doi.org/10.1016/S0364-5916(02)00037-8. 